\title{
TÍTULOS DE LA TIERRA Y NOCIONES POSESORIAS Y DE DOMINIO EN CHARCAS A FINES DEL SIGLO XVI: LA COMPOSICIÓN DEL VALLE DE SUCUSUMA. VIRREINATO DEL PERÚ, 1592-1600
}

\author{
LAND TITLES AND POSSESSION AND DOMINIO IDEAS IN CHARCAS \\ AT THE END OF SIXTEENTH CENTURY. THE COMPOSICIÓN \\ OF SUCUSUMA VALLEY. VICEROYALTY OF PERU, 1592-1600
}

\author{
M. Carolina Jurado*
}

\begin{abstract}
A partir del caso empírico del valle de Sucusuma, el presente trabajo sitúa la actuación de los jueces de composición y venta de tierras en el orden jurídico y en su práctica judicial en vistas a profundizar en las nociones de posesión y dominio de tierras en el distrito de Charcas a fines del siglo XVI. Para ello se examinan las concepciones ligadas a la exhibición de los títulos de la tierra, demandada por las reales cédulas de 1591, y sus antecedentes en la jurisdicción. A continuación, a partir del proceso judicial iniciado por el repartimiento de Chayanta en la audiencia de Charcas, se profundiza en las nociones posesorias y dominiales disputadas en la merced de Sucusuma al relator del mismo tribunal de justicia, el licenciado Juan Díaz Ortiz. Finalmente, se contrasta lo anterior con la actuación judicial de don Pedro Osores de Ulloa como juez de composición charqueño y su relación con las nociones posesorias y de dominio que imbuían los espacios virreinales de fines del siglo XVI.
\end{abstract}

Palabras claves: Composición, merced, posesión, oficiales regios.

Based on the empirical case of Sucusuma valley, this article places the actions of the judges of composicion and sale of land in the juridical order and judicial practice to analyze the notions of possession and dominio of lands in Charcas district at the end of the Sixteenth Century. First, it examines notions linked to the land titles exhibition ordered by the Crown in 1591 and its background in the district. Second, it studies the possession notions linked to the merced and composicion of Sucusuma valley since the judicial process initiated by indigenous repartimiento of Chayanta. Finally it contrasts them with the judicial practice of Don Pedro Osores de Ulloa in Charcas to identify possession ideas in the viceroyalties spaces of the late Sixteenth Century.

Key words: Composición, merced, possession, royal official.

\section{Introducción}

Los procesos de regularización de las posesiones agrarias hispano-criollas sucedidos desde fines del siglo XVI constituyen un hito ineludible en el estudio de la tenencia de la tierra y de las transformaciones de los espacios rurales del virreinato del Perú. Su primera implementación remite a las reales cédulas emitidas en El Pardo el 1 de noviembre de 1591, por las que la monarquía ordenó a los virreyes americanos "que me [h]agais restituir todas las tierras que qualesquier personas tienen y poseen en esas provinçias sin justo y legitimo titulo [h] açiéndolos exsaminar para ello" (AGI, Lima, 215, $\mathrm{N}^{\circ}$ 4, f. 108r). Asimismo, era voluntad real admitir a composición las tierras indebidamente poseídas por los vecinos hispano-criollos, quienes, mediante un pago concertado, obtenían un título de dominio válido respecto de las mismas. Ejecutadas solo 20 años después de la concentración forzada de las poblaciones indígenas a pueblos de reducción, las reales cédulas de 1591 también afectaron la mermada territorialidad de los repartimientos de indios del virreinato peruano. Si bien la composición excluía a los grupos indígenas, cuyo dominio legítimo de sus tierras era reconocido por la monarquía, sus territorios debían inspeccionarse y asignarse según estrictos cálculos demográficos; incluso, los jueces de comisión podían restituir a los repartimientos las tierras ocupadas de hecho. Sin embargo, las inspecciones hallaron tierras consideradas "excedentarias" o "sobras", que fueron adjudicadas a la Corona y vendidas en subasta en beneficio de la Real Hacienda (Jurado 2021).

* CONICET-Instituto Ravignani, Universidad de Buenos Aires. Dirección postal: Espora 390, Témperley. Buenos Aires, Argentina. Correo electrónico: jurado_carolina@yahoo.com.ar 
Con algunos importantes antecedentes que analizaron o publicaron documentación que demostraba el impacto de las composiciones de tierras hispano-criollas en las tierras indígenas, desde fines de la década de 1990 la historiografía histórica y etnohistórica acerca del virreinato del Perú profundizó el estudio del gran despojo provocado desde las primeras composiciones del siglo XVI por el traspaso a manos de hispano-criollos de muchas de las tierras que hasta el momento habían defendido con éxito los repartimientos de indios (Amado 1998; Borchart de Moreno 1980; Challco Huamán 1994; Glave 2009; Hostnig et al. 2007). En particular en el distrito de Charcas, las investigaciones se abocaron preferentemente al análisis de procesos judiciales impulsados por las autoridades indígenas tras los distintos procesos de composición y venta de tierras en vistas a recomponer la territorialidad de diversos repartimientos de indios. Así, el examen del impacto de las primeras composiciones de tierras hispano-criollas en el repartimiento de Chichas y en los corregimientos de Chayanta y Pacajes, junto con la publicación de documentos relativos a sus efectos en los repartimientos de Visisa y Sacaca, evidenciaron el despojo provocado por la venta de terrenos indígenas "sobrantes" así como por la regularización de las usurpaciones de hecho (Jurado 2007, 2014; Morrone 2015; Palomeque 2010; Platt et al. 2006). Asimismo, la documentación hallada para el repartimiento de Paria permitió a Mercedes del Río demostrar que la inspección llevada adelante por el juez de comisión charqueño, fray Luis López, recogió información oral que daba cuenta de una territorialidad étnica dinámica y actualizada. En ese sentido, la autora propuso que las visitas llevadas adelante en el marco del primer proceso de composición constituyeron un campo de tensión y negociación en donde los líderes indígenas pretendieron confirmar sus derechos tradicionales a tierras consideradas "de origen", sumadas a las donaciones coloniales, las tierras del estado incaico y las otorgadas por el virrey Toledo (del Río 2005: 135).

En este contexto, la composición de las tierras de Sucusuma, situadas a orillas del río Caine (Charcas), por parte de dos jueces de comisión sucesivos entre 1592 y 1597, confirma la tendencia señalada por la historiografía de avance hispano-criollo en los territorios indígenas, al haber sido reclamadas por los integrantes del repartimiento de Chayanta como suyas "desde ab initio" (ABNB, EC, 1592, N 11, f. 1r). Un año antes del arribo de la primera comitiva de composición, los integrantes del repartimiento de Chayanta habían pleiteado infructuosamente en la real audiencia de Charcas por la anulación de la cesión de Sucusuma al licenciado Juan Díaz Ortiz, cuyo dominio fue confirmado por los jueces de comisión. Las tierras en disputa, pertenecientes al nicho ecológico de valles mesotérmicos, eran productoras de maíz, ají, algodón y vid, productos que podían destinarse al mercado potosino así como a sustentar las obligaciones políticas asociadas al liderazgo en los Andes. El proceso judicial expuso ante el tribunal charqueño el uso que el Tawantinsuyu había dado a las tierras de Sucusuma como chacras productoras de maíz para alimentar a sus guerreros. Gracias a ello, Sucusuma constituye en la historiografía andina la ejemplificación de las complejas transformaciones laborales y territoriales implementadas en territorio de la antigua Confederación Qaraqara-Charka tras la conquista incaica, al ser tierras cultivadas por los camayos de Chayanta en beneficio del Cusco (Assadourian 1994: 149-150; Platt et al. 2006: 511-513, 623-632). Retomando la propuesta de la existencia de reclamos indígenas a territorialidades dinámicas y actualizadas, se considera en este trabajo que el reclamo del repartimiento de Chayanta por el dominio de las tierras de Sucusuma constituyó una expresión de aquello que Assadourian denominó transiciones en el mundo empírico simbólico indígena, al condensar cambios y nociones indígenas en disputa en torno a derechos de posesión y dominio de las tierras que anteriormente habían sido explotadas en beneficio del Inca (Assadourian 1994: 99).

$\mathrm{Al}$ arribar las comitivas de composición y venta de tierras al distrito de Charcas, las poblaciones indígenas esgrimieron, disputaron y reactualizaron sus ideas y demandas por los derechos a las tierras; también lo hicieron los oficiales reales y vecinos hispano-criollos. En ese sentido, recientes investigaciones abordan los procesos de composición como un campo de negociación y disputa de intereses; una arena donde se confrontaron distintas concepciones respecto de la posesión de la tierra y cuyo ritmo estuvo ligado a las acciones y omisiones de la esfera virreinal, el ambiente geográfico, la demografía y el desarrollo económico de las jurisdicciones de cada uno de los virreinatos de la monarquía castellana (Carrera Quezada 2018: 29-30). El reclamo referente a Sucusuma también constituye un caso empírico ilustrativo en ese sentido, pues movilizó otros sentidos relativos a los derechos de posesión y dominio 
hispano-criollos en disputa. Así, la residencia del juez de composición y venta de tierras del distrito de Charcas, don Pedro Osores de Ulloa, contuvo una imputación relativa a la composición de las tierras de Sucusuma, pues las mismas "se debieran dar por vacas por ser notoriamente defectuoso el titulo que de [e]llas tenia el liçençiado Juan Diaz, relator de la real Audiencia”. El cargo precisaba que, para lograr la amistad del relator, Osores de Ulloa había considerado que el título esgrimido bastaba para componerse, aceptando un pago que representaba menos de la décima parte del valor que ofrecía otro vecino que aspiraba a adquirirlas en subasta. Según los testimonios contenidos en la residencia, lo anterior demostraba que Osores de Ulloa había guiado su administración de justicia por pasiones particulares, damnificando a la Real Hacienda (AGI, Lima, 215, No 4, f. 143r).

Asimismo, la denuncia e imputación pusieron el foco en los títulos de la tierra, cuya demanda de exhibición se contenía en cuatro reales cédulas del 1 de noviembre de 1591. En ellas, los términos sin justo y legítimo título o sin título válido y legítimo calificaban la posesión defectuosa de la tierra, reuniendo tanto la posesión de hecho -apropiación de baldíos o de tierras comunales indígenas, límites excedidos-, la posesión de mala fe -aquella en la que el poseedor conocía los vicios de su posesióncomo las posesiones indebidamente documentadas. En estos casos, de acuerdo con las disposiciones reales, las tierras revertían a los indígenas -para su reproducción social contemporánea o futura- $\mathrm{o}$ a la Corona. Así, la segunda real cédula de 1591 exhortaba a los vecinos hispano-criollos a exhibir los títulos, advirtiendo que, "amparando a los que con buenos titulos y recaudos o justa prescripcion poseyeren, se nos buelban y restituyan las demas" (Recopilación Leyes de Indias, Libro IV, Título 12, Ley ${ }^{14}$ ). El texto expresaba la tensión entre el deseo de la Corona de apropiarse de las tierras y su voluntad de proteger los derechos de los poseedores impidiendo cualquier perturbación que pusiese en duda el equilibrio existente. En ese sentido, la doctrina jurídica del ius commune relacionaba la garantía de la posesión con la garantía de paz -objetivo que, incluso, predominaba por sobre la protección de justicia-(Hespanha 2015). Entonces, en esta formulación, la Corona protegía la posesión con "buen" título así como la posesión regida por la prescripción adquisitiva prevista en el derecho común -que, en términos generales, requería buena fe del poseedor, existencia de título y posesión continua, pacífica y en nombre propio- (Hespanha 2015). Sin embargo, por tercera real cédula permitió a los poseedores sin justo título (y a aquellos que quisieran confirmación) una nueva titulación a cambio del pago de una cantidad concertada, o composición. A los poseedores de hecho o sin títulos legítimos que se negaran al pago, en cambio, la Corona ordenaba quitarles las tierras para subastarlas con aquellas no ocupadas ni repartidas, o baldías (Solano 1991: 274-275).

El llamado a que los vecinos hispano-criollos exhibieran los títulos de las tierras situaba la variada situación agraria -que incluía ocupaciones de hecho, posesión natural, posesión de buena o de mala fe, dominio directo, dominio útil, distintos tipos de enfiteusis, entre otras- bajo la mirada de los jueces de comisión nombrados por la autoridad virreinal para ejecutar las disposiciones reales. Lo anterior significaba que el juez valoraba la legitimidad y la justicia de cada una de las situaciones y de los títulos esgrimidos, los amparaba (o no) y realizaba la composición o llevaba adelante la puja de posturas durante la subasta de las tierras. En ese sentido, las controversias en torno al accionar del juez de comisión en la composición de las tierras de Sucusuma permiten dar cuenta de nociones variadas y mutables de los derechos de posesión de la tierra, ligadas a las modificaciones impulsadas por las cambiantes relaciones sociales del espacio agrario charqueño. El testimonio que sustentó la imputación formalizada en la residencia ligaba los derechos posesorios con el carácter jurídico del título originario, poniendo en consonancia las nociones de algunos vecinos y oficiales hispano-criollos con las disposiciones regias de fines del siglo XVI. Pese a ello, don Pedro Osores de Ulloa, vecino potosino y juez de comisión, distaba de compartir las concepciones de sus detractores. Incluso, si se incorpora al análisis las concepciones acerca de la posesión de la tierra que el valle de Sucusuma había movilizado años antes con ocasión del pleito dirimido en la audiencia de Charcas, se abre un abanico contrastante de nociones y sentidos de los derechos de posesión y dominio en dimensión diacrónica que suma nuevas directrices de análisis.

En vistas a situar la actuación de los jueces de composición y venta de tierras en un orden jurídico y en una práctica judicial atravesada por distintas nociones en torno a la posesión y el dominio de tierras específicas, en primer lugar se examinan las concepciones posesorias ligadas a la titulación que 
enmarcaron la demanda regia de exhibición de los títulos de la tierra, tratando de vislumbrar en qué consistían y qué características tenían los títulos "justos y legítimos" a fines del siglo XVI. A continuación se exploran otras nociones en disputa acerca del dominio y la posesión, a partir del proceso judicial iniciado por las autoridades indígenas del repartimiento de Chayanta en vistas a la anulación de la merced de las tierras de Sucusuma al licenciado Juan Díaz Ortiz. En ese sentido, y retomando el enfoque histórico y relacional de los "derechos de propiedad" propuesto en investigaciones que abordan regiones de España y Francia entre los siglos XVI y XIX, se consideran los derechos de posesión y dominio en su carácter dinámico y plural, en tanto reflejo de las relaciones sociales (desiguales) entabladas en torno a las cosas (Congost 2007; Izquierdo Martín 2007). Finalmente, se indaga el juicio de residencia del juez de comisión don Pedro Osores de Ulloa con el objeto de identificar patrones de comportamiento en su praxis judicial y su relación con las nociones posesorias y de dominio que imbuían el espacio virreinal a fines del siglo XVI.

\section{Justos y legítimos: en torno a la demanda regia de exhibir los títulos de las tierras}

La octava imputación formalizada en el juicio de residencia de don Pedro Osores de Ulloa como juez de composición y venta de tierras dirigió la mirada a los títulos esgrimidos para demostrar la posesión de derecho de las tierras de Sucusuma. En ese sentido, según el cargo, las tierras

"se debieran dar por vacas por ser notoria-
mente defectuoso el titulo que de [e]llas
tenia el liçençiado Juan Diaz relator de la
Real Audiencia que solo fue una merced que
le hiço de [e]lla el cavildo de la çiudad de
La Plata" (AGI, Lima, 215, N $N^{\circ}$, f. 143r).

De acuerdo con el expediente, la imputación se sustentó en la declaración de Diego de Adrada, escribano de la comitiva, quien calificó al título originario como notoriamente defectuoso ${ }^{1}$. Si en el siglo XVIII el título se definía como la "demostración auténtica del derecho, con que se posee alguna hacienda o bienes" (Diccionario de Autoridades 1726-1739); para 1611 su definición carecía de esa precisión, al considerarse el título como el "derecho que cada uno tiene a una cosa" (Cobarruvias
Orozco 1943 [1611]: f. 45v). Lejos estamos de la concepción contemporánea del dominio perfecto reconocido mediante escrituras legales y registradas en un catastro, que fue ganando espacio recién en el siglo XIX (Congost 2007: 15-18). Por el contrario, el escribano real pudo haber querido significar que el derecho esgrimido carecía de validez pues el defecto notorio de título radicaba en haber sido "solo" una merced capitular.

En términos generales, la posesión y el dominio en los virreinatos americanos tuvieron el mismo tratamiento que en el derecho común y en el derecho propio castellano, aunque el dominio de bienes inmuebles como tierras, aguas y minas adquirió un tratamiento peculiar derivado de las bulas alejandrinas (Barrientos Grandón 1999: 8186). Se consideraba que el dominio era la facultad jurídica de tener, poseer, usar y disponer de alguna cosa, con las limitaciones impuestas por el derecho o convención. Como la definición sugiere, consistía en un complejo de derechos y deberes de contenido fluido, alejado de un derecho pleno y exactamente definido sobre una cosa objetivamente identificada. Por ello, la doctrina solía distinguir distintos tipos o especies de dominio sobre las cosas, lo que explicaba que pudiese haber más de un señor de la misma cosa. Por otro lado, la posesión, vinculada con la idea de actos materiales, era aquel derecho por el que alguien tenía un verdadero poder sobre una cosa, refiriendo también a una amplia gama de situaciones (Cobarruvias Orozco 1943 [1611]: f. 326r; Hespanha 2015).

Con excepción de la tierra de dominio indígena, las bulas pontificias concedidas por Alejandro VI habían otorgado a la Corona castellana la soberanía de las tierras descubiertas y por descubrir, conceptuadas desde entonces como bienes de realengo. Enmarcada en esta doctrina, desde los primeros momentos la Corona recompensó los servicios prestados por los conquistadores con tierras en vistas a implantar una política de población. Las concesiones se llevaron a cabo mediante prerrogativas contenidas en las capitulaciones entre un particular y la Corona, provisiones generales o particulares, mediante las Ordenanzas de descubrimiento y nueva población [1573] y, sobre todo, mediante cédulas ordinarias o extraordinarias de gracia o merced. Estas eran donaciones graciosas que hacía el monarca de determinado bien realengo con el fin de recompensar a un vasallo; en ellas, la tierra se ligaba a la idea de reconocimiento de los méritos de los particulares, 
con quienes se establecía una relación contractual (Solano 1991: 16). Los repartos de tierras debían realizarse sin perjuicio de los indígenas y tenían un carácter no oneroso; a cambio se imponían ciertos requisitos, entre los que figuraban un plazo para efectuar la ceremonia de posesión, la vecindad, el cultivo de tierras de sembradío, entre otros (Mariluz Urquijo 1978; Ots Capdequi 1959). Para 1630 el jurista Antonio de León Pinelo (1922 [1630]: ff. 170v-171r) identificaba tres títulos utilizados en los virreinatos americanos para otorgar tierras, evaluando la necesidad de su confirmación real. Fundamentándose en la real cédula de 1531, el jurista sostenía que el primero de ellos, los títulos de gracia y merced dadas en remuneración de servicios, debía llevar la confirmación del rey dentro del año y medio de la fecha de la cédula. Pero debido a la decisiva gravitación que tuvieron los cabildos en el otorgamiento de mercedes durante los primeros años, pocos eran los españoles que tuvieron un título emanado directamente del rey. Incluso, admitía León Pinelo, los virreyes daban tierras a discreción, considerando que "su titulo era bastante", aun cuando debía seguirse la orden general de confirmar todas las mercedes de tierras (León Pinelo 1922 [1630]: f. 170v).

Con importantes antecedentes, las reales cédulas de El Pardo de 1591 demandaron la exhibición ante un oficial real de los títulos que asentaban por escrito los derechos de dominio sobre la tierra. Debe señalarse que los juristas exceptuaban de la titulación a los indígenas, para quienes bastaba la posesión sin título, como lo defendía entre otros Diego de Avendaño (Barrientos Grandón 1999: 86). Para el virreinato del Perú, la referencia más temprana relacionada con la exhibición de los títulos de las tierras ante oficiales reales se remonta a 1565 . Por cédula, el rey solicitaba a la audiencia de Charcas que enviara una Relación detallando los títulos que tenían los vecinos de la ciudad de La Plata a quienes el virrey conde de Nieva (1560-1564) había intentado quitar las tierras por haber sido cedidas por el cabildo de la misma ciudad (Libros registros 1992, I: 30). También en 1578 la Corona demandó a la audiencia de Quito, en particular, y luego por real cédula a las restantes jurisdicciones, que los vecinos exhibieran los títulos de las tierras y que se quitase la posesión de hecho; orden implementada por el virrey del Perú Fernando Torres y Portugal en 1587 (Encinas 2018 [1596]: f. 68; Levillier 1924,
X: 273; Recopilación Leyes de Indias, Libro IV, Título 12, Ley 14). Asimismo, la real cédula del 8 de marzo de 1589 insistía en que se amparase la posesión con legítimos títulos y, finalmente, la orden se reiteraba en las cuatro reales cédulas de El Pardo del 1 de noviembre de 1591. En la primera de ellas, Felipe II mencionaba confusión y exceso en el proceso de distribución de la tierra por culpa y omisión de virreyes, audiencias y gobernadores, los que habían permitido que algunos vecinos, con ocasión de las mercedes, realizaran ocupaciones de hecho, mientras que otros las poseían con "titulos fingidos e invalidos de quien no tuvo poder ni facultad para poderselas dar" (Solano 1991: 273). En su segunda real cédula, el rey ordenaba a los virreyes y presidentes de audiencias pretoriales que "señalen término competente para que los poseedores exhiban ante ellos y los ministros de sus audiencias que nombraren los titulos de tierras, estancias, chacras y cavallerias" (Recopilación Leyes de Indias, Libro IV, Título 12, Ley 14). En sintonía, el virrey del Perú don García Hurtado de Mendoza mencionaba en su correspondencia de mayo de 1592 la existencia de poseedores "sin titulos bastantes" (Zavala 1978, I: 181); mientras que en 1630, al recordar el proceso de composición de 1591, el jurista León Pinelo (1922 [1630]: f. 171r) calificaba los títulos hallados como no "tan justificados". Su opuesto eran los títulos válidos, justos, verdaderos y legítimos, exigidos por las reales cédulas de 1591 pero sin precisar sus características o las esferas jurisdiccionales emisoras que los volvían legítimos. Pese a ello, el escribano real Diego de Adrada no dudó en calificar de notoriamente defectuoso el título de las tierras de Sucusuma, atribuyendo el defecto a su "sola" condición de merced capitular.

Para el virreinato del Perú, al menos desde la década de 1560 se hallan referencias de la preocupación de la monarquía por la mercedación realizada por los virreyes en el distrito de la audiencia de Charcas, solicitando a su máximo tribunal una Relación con el detalle de las mercedes, los servicios meritorios premiados y su posible perjuicio de terceros (Libros registros 1992, I: 30). En cambio, las esferas virreinales peruanas mostraron especial preocupación por las mercedes otorgadas por los cabildos de españoles, cuyas prerrogativas venían siendo limitadas por la monarquía desde 1558-1559. En la década de 1570, el virrey don Francisco de Toledo (1569-1581) detallaba que los oficiales regios 
"han permitido que los cabildos las den y repartido ellos todo lo que [h] avia que se pudiese estimar en algo, lo uno por contentar la gente (...) lo otro por no osar yr contra los encomenderos y cabildos" (Levillier 1924, V: 324-325).

En ese sentido, por real cédula de 1572 la monarquía recordaba que los presidentes de las reales audiencias -junto con los virreyes- eran las autoridades encargadas de la distribución de tierras y solares (Solano 1992: 215-216). También el virrey Fernando Torres y Portugal escribía en 1587 que

"los Cabildos de las ciudades y corregidores de [e]llas [h] an hecho mercedes de tierras en sus distritos a particulares y otros las han tomado por su mano y que son en cantidad lo qual no podian ni deuieran hazer aunque todas fuesen valdias" (Levillier 1924, X: 273).

A continuación, el virrey informaba su decisión de revocar las mercedes dadas por cabildos y corregidores de españoles, instruyendo el examen de los títulos originados en dichas esferas. La respuesta regia demoró dos años y se tradujo en la real cédula de 1589 por ello se determinó que los virreyes y presidentes revocaran las gracias de tierras dadas por los cabildos y las admitieran a composición (Recopilación Leyes de Indias, Libro IV, Título 12. Ley 20) ${ }^{2}$.

Teniendo en cuenta lo anterior, una posible interpretación del testimonio de Diego de Adrada, al considerar notorio el defecto de título de las tierras de Sucusuma, dirigiría la mirada a la institución capitular que, para 1592, ya no contaba con la aprobación de la Corona para otorgar tierras realengas. En ese sentido, la notoriedad de la imperfección sugeriría que el poseedor no podía esgrimir un estado de ignorancia del defecto, proyectando la figura de posesión de mala fe en el caso de Sucusuma. De acuerdo con los juristas del derecho común, esta condición, en donde el poseedor sabía que su posesión no se conformaba a derecho pues conocía los vicios que ella padecía, lo excluía del beneficio de prescripción de dominio (Hespanha 2015). De ese modo, si una de las reales cédulas de 1591 amparaba las tierras con buenos títulos y las que se ajustaban a prescripción, la posesión de mala fe alejaba al licenciado Díaz Ortiz del amparo regio. En ese sentido, no solo el escribano interpretaba de ese modo la situación sino también uno de los vecinos que había ofertado una cuantiosa suma para quedarse con las tierras. Sin embargo, el juez de comisión aceptó el concierto, componiendo Sucusuma con su poseedor. ¿Acaso tenía otras directrices dictadas por la esfera vicerregia?

El 11 de octubre de 1594 el general don Pedro Osores de Ulloa recibió del virrey su Comisión como juez de composición y venta de tierras. Junto con las Instrucciones (1594), constituyen el corpus normativo vicerregio orientador del accionar del segundo juez de comisión del distrito de Charcas. Ambas mantenían el espíritu de las reales cédulas de 1591, instando al juez a que, con prudencia, obtuviera la mayor cantidad de ingresos posibles para las necesidades financieras de la monarquía. En ese sentido, fueron las Instrucciones las que mencionaron que los poseedores debían presentar los títulos originarios de las tierras, enfatizando que, de lo contrario, la Relación que se debía enviar a Lima precisara si eran posesiones de hecho (AGI, Patronato, 191, R. 14, No 2, ff. 1v-2r). Pese a ello, ni la Comisión ni las Instrucciones incluyeron una descripción de los títulos a hallar.

Contrasta lo anterior con las Instrucciones [1598] que el presidente de la audiencia de Guatemala otorgó al comisario que implementaría las reales cédulas de 1591 en esa jurisdicción. En ellas, el magistrado clasificó las acciones a seguir según los títulos hallados o su ausencia, determinando que, para decidir la calidad de los títulos, "no hay que mirar en los años en que se dieron los dichos titulos, sino a las personas que los dieron". Así, precisó que los títulos válidos y bastantes eran aquellos dados por la real audiencia de Guatemala y sus presidentes, mientras que aquellos dados por oidores durante su visita de la tierra se declaraban inválidos. También eran "nulos e invalidos" aquellos emitidos por ayuntamientos y cabildos, aunque el presidente interpretaba que el rey los admitía a composición (Solano 1991: 282).

La normativa del virrey Hurtado de Mendoza resulta, por contraste, llamativamente vaga, más aún al considerar que los primeros jueces de comisión nombrados en el virreinato del Perú habían demandado al virrey algunas precisiones acerca de temas específicos. Para resolverlas Hurtado de Mendoza había convocado en noviembre de 1593 a reconocidos oficiales para tratar semanalmente, en su presencia, las dudas surgidas en lo local (Glave 
2014). Una de ellas focalizaba en los títulos de las tierras, al consultar los jueces "Qual se podra tener por buen titulo en los españoles y si lo sera el de qualquier virrey o gobernador o prescripçion ligitima y qual se podra tener por tal" (AGI, Lima, 132, s/f). Consultado por el virrey, el doctor Alberto de Acuña, abogado general de los indios, respondió la duda considerando que tenía "por sufiçiente titulo el de qualquier virrey o gobernador", sin olvidar que "tambien pareçe por las hordenanças de las audiencias" que ellas tenían poder para conceder las tierras (AGI, Lima, 132, s/f).

Frente a ello, la vaguedad de las disposiciones vicerregias otorgadas al juez Osores de Ulloa a fines de 1594 podría comprenderse en el marco de aquello que los juristas del derecho común sostenían como principio rector de la conducta de todo magistrado: la garantía de paz. En palabras del virrey,

"si sobre algunas tierras, estançias, biñas o exidos de molinos hubieren algunos pleitos entre partes bos [Osores de Ulloa] conpondreis con el que las poseyere" (AGI, Lima, 215, No 4, f. 109v).

Esta orden del virrey podría tanto indicar intereses de gobierno propios de la esfera vicerregia -como la estabilidad de su jurisdicción e, incluso, la creación de redes de lealtad extendidas (Cañeque 2001: 39-40)- como nociones vicerregias de los derechos de posesión y dominio. Retornando al caso empírico de las tierras de Sucusuma, la falta de preceptos vicerregios explícitos y unívocos que guiaran al juez de comisión en su accionar en torno a los títulos hallados lo introducía de lleno en las disputas de nociones posesorias y dominiales que, incluyendo las propias, se desplegaban en cada concierto individual. Como se aborda a continuación, las tierras de Sucusuma movilizaron distintas concepciones a considerar.

\section{Nociones de posesión y dominio en torno a la merced de Sucusuma}

Tras emitirse su Comisión, don Pedro Osores de Ulloa realizó la ceremonia de acatamiento en la ciudad de La Plata el 9 de noviembre de 1594. Como se señaló, el virrey Hurtado de Mendoza otorgó un rol clave al juez de comisión, al ser quien debía concertar (o no) la composición caso por caso de modo individual con los poseedores o con los aspirantes a serlo en el terreno. Conforme con el juez, al arribar a cada distrito su tarea iniciaba con el pregón que anunciaba un plazo de días para que los poseedores llevaran sus títulos y luego procedía a su examen. El general Osores de Ulloa era un oficial que pertenecía al círculo de confianza del virrey pero con una sólida inserción en la sociedad charqueña, al haberse desempeñado previamente como corregidor de La Plata y villa de Potosí y como teniente de capitán general en la jurisdicción (Jurado 2016). Sin embargo, ni su pertenencia social ni su vara de justicia lograrían convencer a la totalidad de los poseedores de acercarse al juez con sus títulos, debiendo este intimarlos con el pago de costas (AGI, Lima, 215, R. 4, f. 149r). En estos casos, además de los poseedores de hecho -carentes de título alguno-, la resistencia pudo haber expresado cierto desentendimiento u oposición a la potestad del oficial regio para concertar cánones por el dominio de la tierra en una jurisdicción que aportaba importantes réditos económicos a la monarquía con su minería de plata.

En cambio, como tantos otros poseedores, el licenciado Juan Díaz Ortiz acercó a la comitiva su título de merced de cien fanegadas de sembradura de maíz en las pampas de Quiballane, en los valles de los arroyos Araria y Vatavata, la quebrada de Chilcaoma, la pampa Culchabamba, Hincota, Cuiquibamba, Calaota y Sucusuma (ABNB, EC, $1592, \mathrm{~N}^{\circ} 11$, f. 20r). La misma acción había realizado con anterioridad, entre 1592 y 1594, ante el primer juez de comisión de composición y venta de tierras de Charcas, fray Luis López, obispo de Quito. En ese entonces, tras examinar el título, el obispo compuso las tierras por 250 pesos ensayados; en cambio, su sucesor, el juez Osores de Ulloa, logró un nuevo concierto por el doble de esa cifra. Como se mencionó, la composición de estas tierras significó para Osores de Ulloa uno de los 20 cargos formalizados en su juicio de residencia, bajo la acusación de aceptar un título "notoriamente defectuoso". Sumado a la denuncia por las pasiones particulares del juez, ¿qué directrices jurídicas, qué elementos de la práctica judicial, qué argumentaciones y nociones acerca de la posesión de derecho pudieron haber motivado a dos jueces de comisión a aceptar en composición un título (por algunos) cuestionado? Las respuestas no son sencillas pues subyace a ellas el problema metodológico de rastrear el diálogo y los argumentos vertidos de modo oral en el concierto individual 
de composición. ¿Cómo acercarse a las variadas concepciones relativas a la posesión y dominio de la tierra e, incluso, a las nociones específicas que se movilizaron en el terreno en relación con el caso empírico seleccionado? Retrotraernos al proceso de mercedación de las tierras en 1592 y ahondar en las nociones que rodearon la merced como título originario quizás puedan brindar caminos posibles para arribar a algunas respuestas.

De acuerdo con el corpus documental, el 8 de enero de 1592 Juan Díaz Ortiz se presentó ante el cabildo de la ciudad de La Plata solicitando una merced de tierras. En la petición se señalaba que el relator necesitaba las tierras

\section{"para [h]aberme de sustentar con mi casa e familia" y para que "pueda hazer heredad y sementera con que abunde esta republica de bastimentos" (ABNB, EC, 1592, $\mathrm{N}^{\circ} 11$, ff. $8 \mathrm{r}-8 \mathrm{v})$.}

Díaz Ortiz precisaba a continuación los sitios específicos donde podrían señalársele las fanegadas de sembradura de maíz, argumentando su lejanía relativa con los pueblos de indios de la región (ABNB, EC, 1592, $\mathrm{N}^{\circ} 11$, f. 8v). Las tierras requeridas se hallaban en las cercanías del río Caine, con una altura aproximada de $1900 \mathrm{msnm}$, en una región de valles secos mesotérmicos, con escasa lluvia y clima caluroso (Ministerio de Medio Ambiente y Agua, SERNAP). La presencia de restos de fortalezas a lo largo del río indicarían que, desde antes de la conquista incaica, la región era codiciada por poblaciones que incursionaban desde el oriente para aprovecharse de los recursos maiceros cultivados por las poblaciones de altura (Platt et al. 2006: 493) [Figura 1].

El proceso judicial se ajustó a las Ordenanzas para audiencias [1563], en donde el rey establecía que, cuando un vecino solicitara tierras en la ciudad de residencia del máximo tribunal, dos regidores capitulares asesorarían al presidente para su otorgamiento (Encinas 2018 [1596]: f. 69r; Recopilación de leyes de Indias, libro IV, Título 12, Ley 8). En ese sentido, el procedimiento incluyó la petición al cabildo, la comunicación al presidente de la audiencia, la comisión a un tercero para la inspección in situ, la citación de testigos, el parecer del juez de comisión, finalmente la merced del cabildo con presencia del presidente de la audiencia y la ceremonia de posesión. Los instrumentos legales generados recuperaron distintas voces que transmitieron sus nociones posesorias en torno a las tierras y, en particular, en torno al valle de Sucusuma. En ese sentido, resultan particularmente sugestivos los testimonios recogidos en el pueblo de San Pedro de Buenavista durante la inspección. El interrogante fue uniforme y

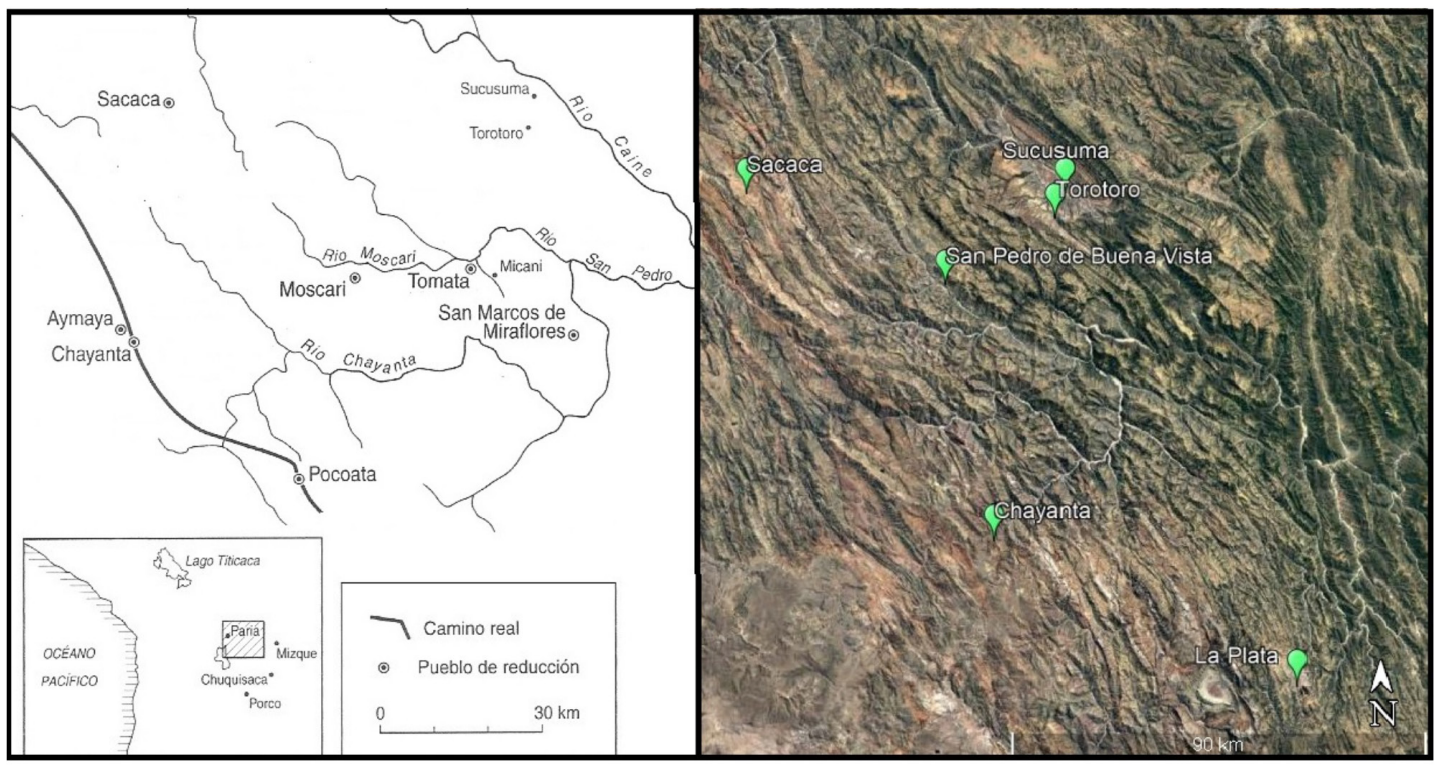

Figura 1. Valle de Sucusuma, distrito de Charcas, virreinato del Perú. Elaboración de la autora con base en Platt et al. $2006: 507$ y Google Earth. 
consultaba si en los valles de Tayapaya, Sucusuma y Calaota existían tierras baldías, apartadas de los pueblos de reducción de indios, y que se pudieran repartir sin perjuicio de los indígenas. Tres testigos españoles reconocieron que las tierras pertenecían al repartimiento de Chayanta, cuyos pueblos de reducción distaban, el puneño, 30 leguas y, el más cercano, 12 leguas de las tierras. Pero, sostenían los testigos, la distancia geográfica impedía a los indígenas labrarlas, con excepción de las tierras más cercanas de Torotoro. Entonces, los testimonios aseveraron que existían alrededor de 30 fanegadas de sembradura de maíz, montuosas y por romper, que se podían otorgar sin perjuicio pues la posesión de los indígenas carecía de valor si no podían efectivamente sembrarlas ni labrarlas. Esta noción coincidía con la idea defendida por algunos juristas del derecho común por la cual la posesión se traducía en actos materiales, como una situación de detención de facto, pública y pacífica, que exigía el ejercicio actual del derecho posesorio -utilizando la cosa corpórea- (Hespanha 2015).

Dos testigos indígenas provenientes del pueblo de Tiquipaya, por medio del intérprete Blas Núñez de Guevara, reforzaron la idea que vinculaba la posesión con los actos materiales, al sostener que

"podra [h]aber tienpo de siete y ocho años que algunos yndios del pueblo de Chayanta se [h] an benido a algunas tierras del dicho valle (...) diziendo que todas las tierras [h] an de ser suyas sin poderlas labrar ni sembrar" (ABNB, EC, 1592, Nº 11, f. 17r.).

Sin embargo, los testigos excedieron el interrogante del oficial, introduciendo una noción que negaba la posesión de derecho a los indígenas de Chayanta pues las tierras habían sido del Inca. En ese sentido, ambos indígenas replicaron que "todo este balle en tiempos pasados fue del Inga y no de particulares" aunque los indios del repartimiento de Chayanta las reclamaran como propias (ABNB, EC, 1592, No 11, f. 17r.). El documento menciona que Sucusuma era también un asiento, ubicado en el valle de Sayapaya (ABNB, EC, 1592, No 11, f. 8r). Este último nombre quizás recuperara el sentido de trabajar para otro, pues de acuerdo con el cronista Guamán Poma de Ayala, el término quechua sayapayac o mandadero designaba a los jóvenes que servían de mensajeros, guarda de ganado y acompañamiento de guerreros y grandes señores, convirtiéndose bajo dominio colonial en un vocablo que refería a aquel que cuidaba de lo que otro le mandaba, de acuerdo con Antonio de la Calancha (Calancha 1638: 134; Guamán Poma 1987 [1615]: 196-197). La información brindada por los testigos indígenas resumía el largo proceso por el que, al imponer su hegemonía, los incas se adjudicaron el derecho de reordenar el espacio a gran escala, enviando colonos de una región a otra, inaugurando terrenos para su explotación intensiva, imponiendo nuevas demandas tributarias que implicaron la redistribución de pastos y chacras, entre otras acciones. Lo anterior se tradujo en una compleja jerarquía de derechos superpuestos de acceso a la tierra, que combinaba las tierras del Tawantinsuyu, de los soberanos, del culto a los $w a k^{\prime} a$, de los linajes distinguidos y de las autoridades locales, de las unidades domésticas y las de control comunal, entreveradas a lo largo del territorio. En Charcas, el reparto de tierras realizado por el Inca Huayna Capac en el valle de Cochabamba constituye un ejemplo clave del proceso de apropiación y reorganización de la tierra y su puesta en producción para las necesidades guerreras, ceremoniales y productivas incaicas. Con importantes diferencias, Sucusuma constituye un espacio apropiado por los incas en territorio de la Confederación Qaraqara-Charka cuya organización laboral aún demanda mayores análisis. Tras la conquista castellana, distintos teólogos y oficiales discutieron los derechos esgrimidos por el monarca a las tierras del Inca y del Sol por derecho de guerra. Así, antes de la década de 1570 la postura de devolver a los pueblos indígenas las tierras que el Tawantinsuyu les había tomado para su propio beneficio se contrapuso tanto a las opiniones que sostuvieron el derecho de sucesión del monarca como a la práctica de los españoles que ocuparon de hecho las tierras del inca. De acuerdo con Assadourian (1994: 215-223), el tenso y contradictorio proceso de apropiación hispano-criolla de las tierras produjo importantes transiciones en la conciencia política y en el mundo empírico simbólico indígena. Lo anterior generó una diversidad de derechos a las tierras del inca, que incluyeron su retención por parte de los indígenas -tanto para preservar sus capacidades de producir excedentes para sí mismos o para pago del tributo-; su completo abandono; su reclamo por parte de líderes indígenas aun luego de retirar a sus colonos; y finalmente su 
apropiación por parte de vecinos hispano-criollos. Las tierras del valle de Sucusuma ejemplifican esta transición en la conciencia de las autoridades y de los integrantes del repartimiento de Chayanta, quienes -de acuerdo con los testimonios- habían (re)iniciado la explotación económica de parte de las tierras en la década de 1580, orientándolas a la producción vitivinícola y tratando de evitar su ocupación por parte de los españoles, en una época marcada por el auge mercantil del polo minero y urbano de Potosí.

Evitando la controversia en torno a los derechos de dominio sobre las tierras del Inca, el juez para la inspección local concluyó que "las dichas tierras, aproximadamente unas 30 fanegadas, son de los dichos yndios de Chayanta" pero, adicionó, podían mercedarse pues no estaban habitadas debido a la distancia geográfica de los pueblos de reducción y por el impacto nocivo de su clima cálido (ABNB, EC, 1592, No 11, ff. 18v-19r). En consecuencia, el 14 de marzo de 1592 el presidente de la audiencia de Charcas en compañía de los regidores del cabildo de La Plata decidieron otorgar en merced 100 fanegadas de tierras "para que las tenga y posea él [licenciado Juan Díaz Ortiz] e sus herederos e sucesores en propiedad y posession" (ABNB, EC, $1592, \mathrm{~N}^{\circ} 11$, f. 20v).

Como muestra del profuso conocimiento que tenían los indígenas de los mecanismos de los tribunales de justicia, menos de 10 días demoraron los líderes del repartimiento de Chayanta en contradecir, por intermedio del protector de naturales Francisco Pérez de la Rinaga, el título de merced y la toma de posesión de las tierras. Lamentablemente, el corpus documental no conserva las palabras vertidas por los testigos presentados por las autoridades del repartimiento, por lo que solo contamos con las nociones jurídicas insertas en el escrito del defensor. En él se omitía el dominio incaico de la región en vistas a enfatizar la posesión inmemorial que el repartimiento de indios tenía de las tierras de Sucusuma, como "posesiones y tierras que de ab inicio aca $[\mathrm{h}]$ emos nosotros y nuestros abuelos y rebisabuelos y demas antecesores tenido y poseido". A ello adicionaban la posesión material actual de las tierras, pues afirmaban tener en Sucusuma sus sembradíos de maíz, ají, algodón y "mas de quarenta mill çepas [de vid] poco mas o menos". Finalmente, un argumento contundente ligaba la posesión con la necesidad que tenían los indígenas de su cultivo para la reproducción social del grupo y el pago del tributo que debían al rey (ABNB, EC, 1592, $\mathrm{N}^{\circ} 11$, f. 1r).

En defensa de la merced el licenciado Díaz Ortiz presentó ante el máximo tribunal una pieza jurídica que recogió las nociones dominiales introducidas por los indígenas de Tiquipaya: los indios del repartimiento de Chayanta no tenían

\begin{abstract}
"a[c]cion ni derecho" sobre Sucusuma pues las tierras habían sido del Inca. Así, precisaba que "por muerte del dicho Ynga quedaron yermas y despobladas y paso el señorio al Rey nuestro señor, de las quales en su Real nombre pudo muy bien vuestro presidente, cabildo y regimiento de [e]sta cibdad darmelas y hazer de [e]llas merced" (ABNB, EC, 1592, $\mathrm{N}^{\circ} 11$, f. 2v.).
\end{abstract}

$\mathrm{El}$ argumento anterior se reforzaba con otra noción de dominio, vinculada a la consideración de las tierras no ocupadas o baldíos como tierra realenga: así, los valles se caracterizaron como tierras que "[h]an estado yermas y despobladas, sin romper, labrar, cultibar y senbrar en ellas" (ABNB, EC, 1592, No 11, ff. 2v-3r).

El relator incorporó otras argumentaciones jurídicas para defender su posesión de derecho, como la distancia geográfica con los pueblos de reducción, la existencia de otras tierras para el sostenimiento indígena, la necesidad de poblar y abastecer la jurisdicción, construyendo semánticamente un paisaje desolado, que adicionaba concepciones europeas relativas a la nocividad del clima. Sin embargo, las dos nociones posesorias principales versaron en torno al derecho regio de reclamar y otorgar dichas tierras como realengas, tanto por haber sido del Inca como por su carácter de tierras baldías. Como se mencionó más arriba, ambas nociones estaban contenidas en las reales cédulas de 1591 y remitían a una larga historia de controversias y procesos de apropiación regia de las tierras americanas. Lamentablemente, el expediente no conserva la sentencia del máximo tribunal charqueño; sin embargo, la imputación formalizada al juez don Pedro Osores de Ulloa da cuenta de que el relator logró conservar las tierras frente al cuestionamiento indígena en 1592. Como adelantamos, también lo hizo tras el paso de dos comitivas de composición y venta de tierras, pocos años más tarde. 


\section{Nociones posesorias y de dominio en la actuación judicial de don Pedro Osores de Ulloa}

El corpus documental resultado de la residencia del general Osores de Ulloa carece de los testimonios completos relevados por el juez Fernández de Recalde pero conserva el detalle de los Cargos formalizados con la nómina de testigos que los fundamentaron. Numerosas imputaciones acusaron a Osores de Ulloa de guiar su administración de justicia por pasiones particulares: la composición de Sucusuma no fue una excepción. El cargo octavo precisaba que

\section{"el dicho don Pedro Çores no admitio la dicha postura [de Juan Gutiérrez de Veas] antes por [h]açer amistad al dicho liçençiado Juan Diaz Ortiz se las dio en quinientos pesos ensayados en que fue dagnificada la Real [H]açienda" (AGI, Lima, 215, $\mathrm{N}^{\mathrm{o}}$ 4, f. 143r).}

De acuerdo al sentido que estuvo en vigor durante el Antiguo Régimen, el término amistad era una manifestación concreta o específica del amor, que integraba al hombre en un determinado círculo de sociabilidad, por lo que constituía un sentimiento del plano de la política. La amistad exigía ser retribuida en una recíproca benevolencia fundada en la comunicación. De acuerdo a Santo Tomás, su relación con la justicia era compleja pues, si el jurista aprehendía afectivamente las relaciones humanas que debía enjuiciar, entonces estaría haciendo su propia justicia, reemplazando el orden instaurado por la naturaleza de las relaciones objetivas. En la tradición jurídica del derecho común, se consideraba que las pasiones de la persona privada pervertían o degeneraban el juicio del juez como persona pública al inclinar su ánimo hacia una de las partes en perjuicio de la otra, alejándolo de su rol de juez imparcial. En particular, se consideraba que el amor, el odio, el temor y la codicia provocaban que el juez perdiera su capacidad de juzgar sin acepción de personas, remitiendo al crimen de corrupción (Garriga 2017; Hespanha 1997).

En ese sentido, la denuncia desvirtuaba la actuación de Osores de Ulloa al administrar justicia guiado por pasiones particulares y revelaba el deseo de Osores de Ulloa, como vecino potosino, de incluir en sus redes de sociabilidad al relator del máximo tribunal de justicia de la región. La acusación también procuraba vincular socialmente a Osores de Ulloa con una figura controversial pues, para el año 1600 cuando se realizó el juicio de residencia, la cabeza de Juan Díaz Ortiz se encontraba expuesta en la plaza de la ciudad de La Plata por haber organizado un año antes la fallida conspiración de Gonzalo Luis de Cabrera para hacerse con las Cajas Reales de Potosí (Levillier 1922, III: 406).

Con asesoramiento letrado, don Pedro Osores de Ulloa elaboró una pieza jurídica destinada a refutar las imputaciones, o Descargos, conservada en el expediente. Los alegatos de defensa desmintieron las acusaciones y brindaron argumentos jurídicopolíticos tendientes a explicar su ejercicio del oficio (Jurado 2016). En ese sentido, la mirada abarcativa y reflexiva que proporcionan los descargos permite situar el caso empírico de Sucusuma en la práctica judicial más amplia del juez de comisión charqueño. Así, su lectura contrastada invita a pensar en las nociones posesorias y dominiales que guiaron su actuación y que distinguieron la posesión de hecho y de derecho, la prescripción de dominio, la existencia de tierras baldías y el destino de la tierra comunal indígena "excedentaria", entre otros.

En consonancia con el paradigma de justicia de la época, la tarea de Osores de Ulloa consistía en interpretar el orden dado, integrando los distintos derechos (regio, local, etc.) caso a caso y en función de las circunstancias que en cada uno concurrían, orientando hacia la solución del problema. En sus instrucciones al virrey del Perú, Felipe II había destacado la flexibilidad en la imposición de las reales cédulas de 1591, ordenando que procediera "en todo con ánimo de afirmar y legitimar la posesión en que hallaréis a cada uno" (Hanke 1978, I: 267-268). La prudencia, la tolerancia y la flexibilidad encaminaban el buen gobierno pues buscaban mantener el equilibrio (Garriga 2006: 151). En ese sentido, inspirado en la garantía de paz, el virrey Hurtado de Mendoza replicó las instrucciones reales en la Comisión de quien ejecutaría las reales cédulas de 1591 en Charcas indicando que usara "de los mejores medios que con vuestra prudençia saveis dar" (AGI, Lima, 215, No 4, f. 109r). Esto no restó capacidad decisoria al juez de comisión, cuya inclinación, por ejemplo, a reforzar derechos comunales de los vecinos potosinos lo llevó a desposeer a Juan de Torres Velázquez y a Pedro Martínez de Jarrista de las ocupaciones de hecho realizadas más allá de los límites declarados en sus títulos, como indica 
el primer descargo de su residencia (AGI, Lima, 215, R. 4, f.145r).

En el caso empírico de las tierras de Sucusuma, los alegatos de Osores de Ulloa y de su asesor legal fueron confusos e imprecisos. Fusionaron la noción de tierra no ocupada o baldío, la previa composición de fray Luis López, un reparto de solares para poblar un futuro pueblo de españoles; y finalmente, esgrimieron la legitimidad del título y la confirmación del virrey del Perú. A ello podríamos adicionar las nociones sobre la posesión de derecho recuperadas en el expediente relativo a la mercedación de Sucusuma, analizado en el apartado anterior, que, vertidas por el licenciado Juan Díaz Ortiz de modo oral, pudieron haber convencido a dos jueces de comisión a componer tierras con un, así conceptuado por algunos contemporáneos, título defectuoso.

$\mathrm{Al}$ insertar el caso específico de Sucusuma en los discursos recogidos en la residencia, se esbozan ciertas regularidades en la actuación judicial del general Osores de Ulloa, guiada como se ha visto por pasiones particulares pero, también, por argumentaciones y nociones más vastas acerca de los derechos posesorios y dominiales en el virreinato peruano a finales del siglo XVI. La formas de comprender la posesión de la tierra a partir de la práctica judicial presentan un renovado interés historiográfico en los últimos años, en particular en investigaciones que ponderan la interrelación entre propiedad y posesión y la importancia de arreglos socialmente establecidos en el marco de comunidades locales en el contexto del derecho común (Bastias Saavedra 2020). La actuación judicial de Osores de Ulloa permite realizar aportes en ese sentido.

La información resultante del corpus documental permite identificar 28 casos de tierras cuya posesión seguía siendo disputada al efectuarse la pesquisa en el año 1600. Sin agotar las posibilidades y como inicio de interrogantes de una investigación en curso, su lectura sugiere que Osores de Ulloa rigió su oficio por una máxima que consistía en no contradecir actos de jurisdicción previos. Así, discurriendo entre los delicados juegos de equilibrio entre el poder real y los poderes corporativos, el juez de comisión confirmó los derechos posesorios resultantes de anteriores procesos de interpretación, ya fueran producto de instancias capitulares o de justicia regia. Incluso, aunque el virrey le ordenó revisar el accionar del previo juez de comisión, el expediente indica que Osores de Ulloa confirmó lo interpretado por fray Luis López, ajustando el canon de composición. Esto se confirma en los casos contenidos en el cargo décimo segundo y que implicaron a los vecinos Hernando Morillas, Pedro Martínez de Jarrista y Pedro de Aguirre. La excepción surge en la primera imputación, en la cual Osores de Ulloa rechazó la decisión del obispo de Quito y subastó las tierras; sin embargo, su particularidad radica en que eran tierras del repartimiento de Puna que el primer juez había considerado indispensables para su reproducción social mientras que Osores de Ulloa las consideró “excedentarias” y las readjudicó en beneficio de la Real Hacienda.

Sin embargo, ¿bastan la protección de la paz y la reafirmación de actos de interpretación previos para comprender la aceptación de la composición de tierras con un título a tal extremo cuestionado que despertó expectativas de desposesión? Retornando a la acusación, nos preguntamos qué otros cuestionamientos implicaba la expresión "que solo fue una merced que le hiço de [e]lla el cavildo de la çiudad de La Plata". Se analizó uno de ellos, dirigiendo la mirada a la institución que emitió la merced, esto es, el cabildo de españoles. Pero, pese al cuestionamiento de las mercedes capitulares, de acuerdo a la información brindada por la residencia, en todos los casos el juez de comisión admitió los instrumentos legales emanados del cabildo de La Plata, dando la posibilidad a los poseedores de concertar un canon por composición en lugar de subastar sus tierras en pública almoneda. Así lo sugiere su octavo descargo, al reivindicar la legítima jurisdicción ejercida por el cabildo en el caso de las tierras de Sucusuma. De acuerdo a él,

\footnotetext{
"estaban dados algunos pedaços por el cavildo de la çiudad de La Plata e por el señor presidente de aquella audiencia, antes que [h]obiese la proybiçion de Su Magestad" (AGI, Lima, 215, R. 4, f. 147v).
}

Como se señaló, las limitaciones reales de las atribuciones capitulares de repartir tierras se retrotraen a 1558-1559 y adquieren notoriedad en la real cédula de 1589; sin embargo, la mercedación de Sucusuma se había guiado por el procedimiento contenido en las Ordenanzas de audiencias de 1563, que ordenaba incluir el parecer de los cabildos en el asesoramiento de los repartos de tierras efectuados por virreyes, gobernadores o presidentes de audiencias. No puede descartarse 
que el discurso vertido por el escribano de la comitiva de composición -quien efectivamente examinó el título original- constituyera un modo de expresar la tensión que existía en la época entre la concepción jurisdiccional del poder -de acuerdo a la cual ciertas capacidades normativas con fuerza legal para el ámbito municipal formaban parte de la potestad de iurisdictio del cabildo, dentro de un orden social corporativo- y, por el otro, el discurso jurídico-político que consideraba a la autoridad regia como única poseedora legítima de esa potestad (Agüero 2013: 158). Las instancias capitulares, controladas por colegios de regidores vinculados a las élites urbanas, tuvieron potestades normativas, judiciales y de gobierno insoslayables. Para un súbdito castellano era imposible eludir el hecho de que la monarquía había confiado la distribución inmediata de las tierras a las audiencias con asesoramiento previo de los cabildos. De este modo, informando o accionando directamente en los repartos, las instituciones municipales mantenían un papel decisivo en el otorgamiento de derechos a la tierra, distribución sensible a los intereses y conveniencias de los capitulares y de sus allegados (Mariluz Urquijo 1978: 33-35). En el examen que llevaba adelante todo juez de composición y venta de tierras decidir sobre el destino de las mercedes otorgadas por los cabildos, y, en última instancia, sobre su gravitación concreta en la estructura agraria de la región circundante se convertía en un asunto delicado. El general Osores de Ulloa optó por confirmarlas. El mismo comportamiento caracterizó al previo juez de comisión, fray Luis López, quien aceptó componer tierras con títulos de merced capitulares, como fueron los casos de Luis Hernández y de Juan de Vera en el corregimiento de Porco, contenidos en los descargos primero y segundo (AGI, Lima, 215, R. 4, ff. 145r-146r).

Otra lectura de la imputación resulta posible y focaliza en la posesión de derecho, sugiriendo que, al sostener que era "solo" una merced capitular, se hacía referencia a la ausencia de confirmación real. Recordemos que León Pinelo (1922 [1630]: ff. 170v-171r) precisaba que las cédulas ordinarias de tierras y solares debían llevar confirmación regia si el título era perpetuo y las tierras de valor considerable. En ese sentido, la merced del relator Díaz Ortiz combinaba ambas, al implicar la heredabilidad de 100 fanegadas de sembradura de maíz de alto valor -si nos guiamos por el ofrecimiento de 6 mil pesos de plata ensayada que se realizó por ellas-.
Finalmente, la acusación podría referir a las nociones jurídicas de la merced como título de dominio. No existía consenso en el derecho común acerca del concepto jurídico de la merced: así juristas como Bartolomé de Albornoz interpretaban la merced como donación pura, nacida exclusivamente de la voluntad libre del monarca mientras que otros, como el jurista Solórzano Pereira, opinaban en favor de su naturaleza contractual o de donación cuasi-remuneratoria de los servicios de los vasallos (Zavala 1935: 267-268). En este caso, la merced con causa meritoria requería un equilibrio entre la potestad del donante y el mérito o el servicio del donatario. Esta naturaleza contractual daba a la merced una fuerza concreta de la que dimanaba su persistencia pro futuro, aunque existiera el criterio de confirmación de las donaciones (Sandoval Parra 2013: 350-377). La tensión señalada más arriba implicaba importantes diferencias en relación a la interpretación de los derechos adquiridos por el donatario, como puede observarse en las discusiones producidas en el virreinato de Nueva España entre los años 1572-1575, ideas quizás difundidas en el Perú a través de los circuitos de comunicación que ligaban entre sí a los distintos espacios virreinales. La polémica había enfrentado al virrey Enríquez, quien sostenía que la merced era un instrumento que otorgaba el dominio útil de las tierras, reservándose siempre al rey el dominio eminente, con la real audiencia de México, tribunal que afirmaba que diez años de posesión efectiva de la tierra equivalían a su dominio pleno (Menegus Bornemann 1994: 208-209).

En Charcas, para el presidente de su audiencia y el cabildo de La Plata, la merced de Sucusuma implicaba la "propiedad y posession" heredable de las tierras, noción deudora quizás de concepciones que interpretaban que con la merced el rey adjudicaba dominio pleno de lo mercedado. En el mismo sentido, el corpus documental evidencia que Osores de Ulloa confirmó los derechos adquiridos por los donatarios pues todos los títulos de merced de origen capitular o regio presentados a la comitiva fueron aceptados en composición. En ese sentido, para Osores de Ulloa la merced se asimilaba a un título "justo y legítimo", que permitía al poseedor concertar un pago moderado sin intromisión de otras posturas que pudieran disputar la posesión. Asimismo, no se debe soslayar la funcionalidad práctico política de confirmar la persistencia temporal de la merced, ligada a la obligación de estabilidad 
social, perpetuación de una sociedad de estados y utilidad de la república-mediante servicios de armas y/o de letras-implícitas en la justicia del rey (Sandoval Parra 2013: 340-341).

Similar fue la praxis judicial de Osores de Ulloa en el caso de las mercedes de tierras que durante la composición debió señalar a los criados Francisco de Velasco y Fernando de Ocampo, por cédulas reales ordinarias e indicación del virrey. Al seleccionar las tierras, el juez explicitó nociones que ligaban la merced, la extensión de lo otorgado y la institución que ordenaba su cesión. Así, el juez precisó que, si por

"sola la costumbre general de los cavildos [h] an dado e podido dar duçientas e trescientas fanegadas de sembradura de mayz e mayor cantidad, mejor e mas justamente las pude y devi dar en cumplimiento de las dichas reales çedulas" (AGI, Lima, 215, R. 4, f. 149v).

En este caso, la coexistencia de nociones vinculadas a la donación graciosa de tierras realengas con otras más recientes de rendimiento fiscal -contenidas en las reales cédulas de 1591- halló en Osores de Ulloa un oficial con capacidad decisoria y creativa a partir del cobro de un canon moderado por componer en simultáneo lo que la merced cedía con validez futura.

\section{Consideraciones finales}

En el presente trabajo hemos querido reflexionar sobre las nociones posesorias y de dominio que distintos actores sociales disputaron en la primera composición y venta de tierras en el virreinato del Perú y, en particular, sobre aquellas que pudieron haber guiado la actuación judicial de don Pedro Osores de Ulloa como juez de comisión del distrito de Charcas. El caso empírico de las tierras del valle de Sucusuma confirma la tendencia señalada por la historiografía relativa a la erosión del dominio territorial de los repartimientos de indios durante su primera ejecución en el virreinato del Perú, como sucedió en el repartimiento de Chichas y Paria y en los corregimientos de Chayanta, Porco y Pacajes, todos ellos en Charcas. En ese sentido, las tierras de Sucusuma fueron reclamadas en la audiencia de Charcas por el repartimiento de Chayanta, cuyos integrantes realizaban un uso material actual de las mismas. Pese a ello, el español Juan Díaz Ortiz obtuvo la confirmación regia de su título de merced mediante el pago concertado durante la inspección de dos jueces de composición. En particular, de acuerdo a la denuncia del escribano de la comitiva, la motivación de la segunda composición de Sucusuma remitía al crimen de corrupción, pues el juez Osores de Ulloa se había guiado por pasiones particulares que inclinaban su ánimo hacia una de las partes.

Asimismo, al insertar la actuación judicial de Osores de Ulloa en el orden jurídico y en su práctica judicial más amplia, la casuística elegida sugirió directrices de análisis adicionales. En ese sentido, se evidencia la importancia que tenían los títulos en el derecho común y en el contexto virreinal del siglo XVI. De ello puede dar cuenta el reiterado deseo de la monarquía de examinar los títulos de las tierras en la jurisdicción analizada y las expectativas y sentidos que éstos generaron en distintos actores sociales. Títulos justos y legítimos y títulos fingidos e inválidos se combinaban con obligaciones ceremoniales, actos materiales concretos, buena $\mathrm{fe}$, perjuicio de poblaciones indígenas, reconocimiento del statu quo, la garantía de paz y arreglos logrados al interior de comunidades locales, entre otros factores, brindando una imagen compleja que demanda nuevos análisis.

Las tierras del valle de Sucusuma, asimismo, movilizaron otras nociones sobre la posesión y el dominio, que distan de oponer representaciones indígenas y españolas dicotómicas en torno a la tenencia y el dominio de la tierra. Así, se señaló que la explotación prehispánica de Sucusuma en beneficio del Tawantinsuyu mermaba los derechos de dominio que los integrantes del repartimiento de Chayanta reclamaban para sí, desde la mirada de algunos testigos indígenas y españoles por igual. Por otro lado, su reclamo como tierras pertenecientes $a b$ origen a Chayanta, fundado en una pretendida tenencia étnica prehispánica de (al menos) parte de ellas, o bien, en la transición operada en el mundo empírico simbólico de la misma población que las había cultivado como camayos, esbozaban otros tantos sentidos acerca de la posesión de derecho en el primer siglo de dominio castellano. Finalmente, lo anterior no limita las concepciones posesorias y dominiales presentes en la sociedad charqueña de fin de siglo, pues al insertar la composición de Sucusuma en el abanico de derechos protegidos por el juez de comisión, de acuerdo a su residencia, el 
general Osores de Ulloa se presenta como un oficial garante de los actos de interpretación previos sobre casuísticas particulares así como de los derechos adquiridos por los donatarios del instrumento jurídico de la merced. Futuras investigaciones podrán comprobar si este fue un comportamiento generalizado entre los jueces de composición de finales del siglo XVI, evaluando el espacio hallado para la disputa de nociones posesorias y dominiales en sus prácticas de justicia.

\section{Agradecimientos}

Esta investigación se desarrolló en el marco de los proyectos UBACyT F-291 y PICT FONCYT 2016-0481. Agradezco la invitación de Germán Morong Reyes y Ana M. Presta a participar del presente Dossier, a Sergio Angeli por sus comentarios a versiones previas del presente trabajo, y a los/as evaluadores/as de la Revista por sus valiosas sugerencias.

\section{Referencias Citadas}

Agüero. A.

2013 “Ciudad y poder político en el Antiguo Régimen. La tradición castellana". En El derecho local en la periferia de la monarquía hispana. Río de la Plata, Tucumán y Cuyo (siglos XVI-XVIII), editado por Víctor Tau Anzoátegui y Alejandro Agüero, pp. 127-163. INHIDE, Buenos Aires. Amado Gonzáles, D.

1998 "Reparto de tierras indígenas y la primera visita y composición general, 1591-1595”. Histórica XXII (2): 197-207.

Assadourian, C.

1994 "Los derechos a las tierras del Inca y del Sol". En Transiciones hacia el sistema colonial andino, pp. 92-150. El Colegio de México-IEP, Lima.

Barrientos Grandón, J.

1999 "Literatura jurídica indiana de derecho privado". Revista de Historia del Derecho Privado 2: 65-88.

Bastias Saavedra, M.

2020 "The normativity of possession. Rethinking land relations in early-modern Spanish America, ca. 1500-1800". Colonial Latin American Review 29 (2): 223-238.

Borchart de Moreno, C.

1980 "Composiciones de tierras en la Audiencia de Quito: el valle de Tumbaco a finales del siglo XVII". Jarbuch für Geschichte Lateinamerikas 17: 121-155.

Calancha, A. de la.

1638 Coronica moralizada del Orden de San Agustin en el Perú con sucesos egenplares en esta Monarquía. Pedro Lacavalleria, Barcelona. http://www.cervantesvirtual.com/ obra/coronica-moralizada-del-orden-de-san-augustin-enel-peru-con-sucesos-egenplares-en-esta-monarquia-/ (10 febrero 2021)

Cañeque, A.

2001 "Cultura vicerregia y Estado colonial. Una aproximación crítica al estudio de la historia política de la Nueva España”. Historia Mexicana 51 (1): 5-57.

Carrera Quezada, S.

2018 Sementeras de papel. La regularización de la propiedad rural en la Huasteca serrana, 1550-1720. El Colegio de México-CIESAS, México.

Challco Huamán, S.

1994 Composición y tenencia de tierras: valle de PaucartamboCuzco: ss. XVI-XVIII. Universidad Nacional Mayor de San Marcos, Lima.
Cobarruvias Orozco, S. de.

1943 [1611] Tesoro de la lengua Castellana, o Española. S. A. Horta, Barcelona.

Congost, R.

2007 Tierras, leyes, historia. Estudios sobre la $<<$ gran obra de la propiedad $>>$. Crítica, Barcelona.

Diccionario de Autoridades

[1726-1739] Real Academia Española. http://web.frl.es/ DA.html (1 marzo 2020)

Encinas, D. de.

2018 [1596] Cedulario indiano. Imprenta de la Agencia Estatal Boletín Oficial del Estado y Real Academia de la Historia, Madrid.

Garriga, C.

2017 "Crimen corruptionis. Justicia y corrupción del ius commune (Corona de Castilla, siglos XVI-XVII)". Revista Complutense de Historia de América 43: 21-48.

Garriga, C.

2006 "Sobre el gobierno de la justicia en Indias (siglos XVIXVII)". Revista de Historia del Derecho 34: 67-160.

Glave, L. M.

2014 "El arbitrio de tierras de 1622 y el debate sobre las propiedades y los derechos coloniales de los indios". Anuario de Estudios Americanos 71 (1): 79-106.

Glave, L. M.

2009 "Propiedad de la tierra, agricultura y comercio, 1570-1700: el gran despojo". En Compendio de historia económica del Perú, editado por Carlos Contreras, pp. 330-345. Banco Central de Reserva del Perú-IEP, Lima.

Guamán Poma de Ayala, F.

1987 [1615] Nueva crónica y buen gobierno, editado por John Murra, Rolena Adorno y Jorge Urioste. Historia 16, Madrid.

Hanke, L. (ed.).

1978 Los virreyes españoles en América durante el gobierno de la casa de Austria. Perú. Biblioteca de Autores Españoles, Madrid.

Hespanha, A.

2015 Como os juristas viam o mundo. 1550-1750. Directos, estados, pessoas, coisas, contratos, açoes e crimes. Create Space, Lisboa.

Hespanha, A.

1997 "La senda amorosa del derecho. Amor y iustitia en el discurso jurídico moderno". En Pasiones del jurista. Amor, 
memoria, melancolía, imaginación, editado por Carlos Petit, pp. 23-73. Centro de Estudios Constitucionales, Madrid.

Hostnig, R, C. Palomino Dongo y J. Decoster

2007 Proceso de composición y titulación de tierras en Apurímac-Perú. Siglos XVI-XX. Austrian Academy of Sciences, Asociación Kuraka, EDITATÚ editores e impresores, Cusco.

Izquierdo Martín, J.

2007 "En nombre de la comunidad. Antropología de la propiedad en el Antiguo Régimen”. En Campos cerrados, debates abiertos. Análisis histórico y propiedad de la tierra en Europa (siglos XVI-XIX), editado por Rosa Congost y José M. Lana, pp. 53-73. Universidad Pública de Navarra, Pamplona.

Jurado, M. C.

2021 "Los baldíos. Derechos posesorios y tierra realenga en el primer proceso de composición en el distrito de Charcas. Virreinato del Perú, 1591-1597". América Latina en la Historia Económica (En prensa).

Jurado, M. C.

2016 "La primera visita y composición de tierras en Charcas a través de la residencia de Don Pedro Osores de Ulloa, juez de tierras del siglo XVI". Indiana 33 (2): 9-30.

Jurado, M. C.

2014 "Un fiscal al servicio de Su Majestad: don Francisco de Alfaro en la Audiencia de Charcas, 1598-1608". Población \& Sociedad 21 (1): 99-132.

Jurado, M. C.

2007 "La legalización de la memoria: una mirada a las composiciones de tierras norpotosinas a fines del siglo XVI". Ponencia presentada en "XI Jornadas Interescuelas / Departamentos de Historia", S. M. de Tucumán.

León Pinelo, A.

1922 [1630] Tratado de confirmaciones reales. Taller Casa J. Peuser, Buenos Aires.

Levillier, R.

1924 Gobernantes del Perú. Cartas y papeles. Imprenta de Juan Pueyo, Madrid.

Levillier, R.

1922 Audiencia de Charcas. Correspondencia de Presidentes y Oidores. Imprenta de Juan Pueyo, Madrid.

Libros registros-cedularios de Charcas, 1563-1717: Catálogo. 1992 Dirección de Víctor Tau Anzoátegui. INHIDE, Buenos Aires.

Mariluz Urquijo, J.

1978 El régimen de la tierra en el Derecho Indiano. Perrol, Buenos Aires.
Menegus Bornemann, M.

1994 "Los títulos primordiales de los pueblos de indios". Estudis. Revista de Historia Moderna 20: 207-230.

Ministerio de Medio Ambiente y Agua, Servicio Nacional de Áreas Protegidas (SERNAP), Estado Plurinacional de Bolivia.

Morrone, A.

2015 "Memoria en la sangre y en la tierra. Liderazgo, sucesión y territorialidad en el sur andino (corregimiento de Pacajes, 1570-1650)". Indiana 32: 205-234.

Ots Capdequi, J.

1959 España en América. El régimen de tierras en la época colonial. FCE, México.

Palomeque, S.

2010 "Los chichas y las visitas toledanas. Las tierras de los chichas de Talina (1573-1595)". Surandino Monográfico 1 (2): 1-71. http://www.filo.uba.ar/contenidos/investigacion/ institutos/ravignani/prohal/SM_002_Articulos/003_ Palomeque.pdf (1 febrero 2021)

Platt, T., T. Bouysse-Cassagne y O. Harris

2006 Qaraqara-Charka. Mallku, Inka y Rey en la provincia de Charcas (siglos XV-XVII). Historia antropológica de una confederación aymara. IFEA-Plural, La Paz.

Recopilación de Leyes de Indias

http://www.filosofia.org/mfa/fae681a.htm (1 marzo 2020).

Sandoval Parra, V.

2013 "La naturaleza jurídica de la merced en la Edad Moderna". Anuario de Historia del derecho español 83: 325-411.

Solano, F. de

1991 Cedulario de tierras. Compilación de legislación agraria colonial (1497-1820). UNAM, México.

Zavala, S.

1978 El servicio personal de los indios en el Perú (extractos del siglo XVI). El Colegio de México, México.

Zavala, S.

1935 Las instituciones jurídicas en la conquista de América. Imprenta Helénica, Madrid.

\section{Fondos documentales}

Archivo General de Indias (AGI)

Lima, 132.

Lima, 215, No 4.

Patronato, 191, R. 14, No 2.

Archivo y Biblioteca Nacionales de Bolivia (ABNB)

Escrituras Coloniales (EC), 1592, No 11.

\section{Notas}

1 A pesar de que el virrey don García Hurtado de Mendoza nombró a Diego de Zúñiga como escribano de comisión, un concierto entre las partes había determinado que, en la práctica, fuera Diego de Adrada quien ejerció el oficio, compartiendo con Zúñiga los derechos que surgían durante la composición de tierras y de extranjeros y venta de baldíos (AGI, Lima, 215, No 4, f. 110r, f. 144r.).
2 El proceso no es lineal y presenta tensiones pues, por real cédula del 8 de mayo de 1589, la Corona sostuvo que "no conviene hacer novedad con los poseedores de tierras, salvo con aquellos que no tuvieren titulo de virrey, audiencia o cabildo o los que tuviesen mas cantidad que la de los titulos" (Recopilación Leyes de Indias, Libro IV, Título 12, Ley 14). 